\title{
Identification and Partial Characterization of a Somatostatin-14 Binding Protein on Rat Liver Plasma Membranes
}

\author{
Steven E. RaPer, ${ }^{1}$ PtYUSh C. Kothary ${ }^{1}$ AND John DelValle ${ }^{2}$ \\ Departments of ${ }^{1}$ Surgery and ${ }^{2}$ Medicine, University of Michigan Medical School, Ann Arbor, Michigan 48109-0331
}

\begin{abstract}
Binding of somatostatin-14 to rat liver plasma membranes was characterized with ${ }^{125}$-labeled[tyr ${ }^{11}$ ] somatostatin-14. Binding at $24^{\circ} \mathrm{C}$ reached a plateau at $50 \mathrm{~min}$ and was reversible by synthetic somatostatin-14. Scatchard analysis revealed a single class of binding sites (affinity constant $=2.4 \pm 0.2$ nmol/L, binding capacity $=148 \pm 0.02 \mathrm{fmol} / \mathrm{mg}$ protein). Specificity for somatostatin-14 was demonstrated by the inhibition of ${ }^{125} I-\left[\right.$ tyr $\left.^{11}\right]$ somatostatin-14 binding by biologically active somatostatin analogs but not by a biologically inactive somatostatin analog or unrelated peptides. The radioiodinated binding site complex could be cross-linked with disuccinimidyl suberate. Analysis by sodium dodecyl sulfatepolyacrylamide gel electrophoresis and gel autoradiography revealed a 70,000-Da band. Dithiothreitol, a reducing reagent, did not alter the mobility of the band, and the band could be abolished in the presence of 10 $\mu \mathrm{mol} / \mathrm{L}$ synthetic somatostatin-14. Covalently crosslinked, iodinated binding protein complexes could be solubilized by the nonreducing detergents Zwittergent 3-12 and 3-([3-cholamidopropyl] diethylammonio)-1propanesulfonic acid (CHAPS). Solubilized complex bound to wheat-germ agglutinin-agarose columns and was eluted by $\mathbf{N}, \mathbf{N}^{\prime}, \mathbf{N}^{\prime \prime}$-triacetylchitotriose. Binding to wheat-germ agglutinin agarose columns was lost after pretreatment with endo- $\beta-N$-acetylglucosaminidase $F$. Binding studies with liver plasma membranes, ${ }^{125} I$ labeled[tyrosine ${ }^{11}$ ]somatostatin-14 and guanine nucleotides showed inhibition of binding in the presence of guanine nucleotides.
\end{abstract}

These results indicate that the purified rat liver plasma membranes contain a specific binding protein for somatostatin-14, the binding protein appears to be glycosylated and somatostatin-14 binding to rat liver plasma membranes may be regulated by $G$ proteins. (Hepatology 1992;16:433-439.)

Received July 10, 1991; accepted March 17, 1992

'This work was supported by National Institutes of Health/U.S Public Health Service grants 1R29 DK 42485 and 5P30 DK 34933 (Michigan Gastrointestinal Peptide Research Center), a Career Development Award from the Society for Surgery of the Alimentary Tract and grants from the Rackham Foundation and the Michigan Memorial Phoenix Project.

Address reprint requests to: Steven E. Raper, M.D., $2922 \mathrm{H}$ Taubman Health Care Center, 1500 E. Medical Center Drive, Ann Arbor, MI 48109-0331.

31/1/38042
Somatostatin-14 (SS-14) was first discovered as an inhibitor of growth hormone secretion. It has since been shown to regulate brain and gut function by paracrine mechanisms $(1,2)$. SS-14 inhibits adenylate cyclase activity in isolated rat hepatocytes and liver $(3,4)$. It also inhibits glycogenolysis and very low density lipoprotein production in the isolated, perfused rat liver $(5,6)$. Taken together, the data suggest the existence of a direct effect of SS-14 on the liver, possibly receptor-mediated (7). SS-14 binding to liver has been reported previously (8). One study using an SS-14 analog showed binding to the liver cell plasma membrane (9), whereas other studies using a dynamic dilution technique demonstrated $9.8 \%$ binding that could not be displaced by synthetic SS-14 (10). In this report, we identified and characterized SS-14 binding sites on rat liver plasma membranes using a conventional direct binding assay and biochemical characterization with a variety of standard techniques.

\section{MATERIALS AND METHODS}

Chemicals. All protease inhibitors, sugars, agarose, wheat germ agglutinin (WGA) and endo- $\beta-N$-acetylglucosaminidase F (endo F) were obtained from Sigma Chemical Co. (St. Louis, MO). SS-14, $\left[\right.$ tyr $\left.^{11}\right]$ SS-14 and all other peptides were obtained from Peninsula Laboratories (Belmont, CA). Disuccimidyl suberate (DSS) and other cross-linking reagents were obtained from Pierce Chemical (Rockford, IL). All reagents used in SDS-PAGE were of electrophoresis grade and were obtained from Bio-Rad Laboratories (Richmond, CA) or from Boehringer-Mannheim (Indianapolis, IN). Radioactive sodium iodide for the radioiodination of [tyr $\left.{ }^{11}\right]$ SS-14 was obtained from Amersham (Arlington Heights, IL). 5'-Nucleotidase, aklaline phosphatase and total protein were assayed with commercial kits obtained from Sigma Chemical Co.

Isolation of Highly Purified Rat Liver Plasma Membranes. Rat liver plasma membranes were prepared from the livers of adult male Sprague-Dawley rats (250 to $275 \mathrm{gm}$ ) (11). Rat liver was homogenized with 10 strokes in a Dounce tissue homog. enizer (Sigma Chemical Co.) containing $50 \mathrm{ml}$ ice-cold buffer $\left(0.5 \mathrm{mmol} / \mathrm{L} \mathrm{CaCl}_{2}, 1 \mathrm{mmol} / \mathrm{L} \mathrm{NaHCO}_{3}, 2 \mu \mathrm{mol} / \mathrm{L}\right.$ leupeptin, 2 $\mu \mathrm{mol} / \mathrm{L}$ pepstatin, $1 \mu \mathrm{mol} / \mathrm{L}$ PMSF and $0.1 \mathrm{mg} / \mathrm{ml}$ bacitracin at $\mathrm{pH}$ 7.5). After three low-speed centrifugations $(2,500 \mathrm{rpm})$, the crude preparation was pooled in a $50-\mathrm{ml}$ ultracentrifuge tube and spun through a discontinuous sucrose density gradient for $2 \mathrm{hr}$ at $25,000 \mathrm{rpm}$ and at $4^{\circ} \mathrm{C}$. The liver plasma membranes 
layered at the interface of $37 \%$ and $41 \%$ sucrose. The plasma membrane fraction collected from the interface was then stored at $-70^{\circ} \mathrm{C}$. Two separate membrane enzyme analyses 5 '-nucleotidase and alkaline phosphatase - were performed in the crude homogenate and the final membrane preparation (11). Membranes were accepted as pure, with at least a 20 -fold increase in enzyme activity per milligram wet weight. Membranes were used immediately or suspended in $50 \mathrm{mmol} / \mathrm{L}$ HEPES buffer ( $\mathrm{pH} 7.4$ ); aliquots were kept at $-70^{\circ} \mathrm{C}$ until ready for use.

Binding Assay. Radiolabeling of the SS-14 analog [tyr ${ }^{11}$ ]SS-14 was performed as described previously with chloramine-T (12). [tyr $\left.{ }^{11}\right] \mathrm{SS}-14(2.4 \mathrm{nmol}),{ }^{125} \mathrm{NaI}(0.5 \mathrm{mCi})$ and chloramine- $T$ were incubated in $0.04 \mathrm{~mol} / \mathrm{L}$ sodium phosphate buffer in a final reaction volume of $100 \mu \mathrm{l}$. The specific activity of the tracer was $\sim 1,000 \mathrm{Ci} / \mathrm{mmol}$. The radioligand was purified by reverse-phase HPLC on a $\mu$ Bondapak C18 column $(0.39 \times 30 \mathrm{~cm}$; Waters Associates, Milford, MA). Elution buffer A was $2 \%$ trifluoroacetic acid and buffer B was $2 \%$ trifluoroacetic acid with $50 \%$ acetonitrile. The column was eluted at a flow rate of $1 \mathrm{ml} / \mathrm{min}$ at room temperature with a protocol of $5 \mathrm{~min}$ at $0 \%$ buffer B, $17.5 \mathrm{~min}$ gradient of $0 \%$ to $70 \%$ buffer B, 10 min at $70 \%$ buffer B and $70 \%$ to $0 \%$ buffer B (13).

Binding of ${ }^{125} \mathrm{I}-\left[\mathrm{tyr}^{11}\right] \mathrm{SS}-14(50 \mathrm{pmol} / \mathrm{L})$ to plasma membrane $(20 \mu \mathrm{g} / \mathrm{ml})$ was carried out in $0.5 \mathrm{ml}$ of binding buffer $\left(1 \mathrm{mmol} / \mathrm{L} \mathrm{NaHCO} \mathrm{N}_{3}, 0.5 \mathrm{mmol} / \mathrm{L} \mathrm{CaCl}_{2}, 2 \mu \mathrm{mol} / \mathrm{L}\right.$ leupeptin, $2 \mu \mathrm{mol} / \mathrm{L}$ pepstatin, $1 \mathrm{mmol} / \mathrm{L}$ PMSF and $0.1 \mathrm{mg} / \mathrm{ml}$ bacitracin) and increasing concentrations of synthetic peptides or nucleotides at $\mathrm{pH} 7.5$ for $50 \mathrm{~min}$ at $24^{\circ} \mathrm{C}$. When the incubation temperature was decreased to $4^{\circ} \mathrm{C}$, no significant specific binding was seen, but a decrease in maximal binding at $37^{\circ} \mathrm{C}$ did appear. Membrane-bound ${ }^{125} \mathrm{I}$-[tyr $\left.{ }^{11}\right] \mathrm{SS}-14$ was separated by centrifugation at $10,000 \mathrm{~g}$ for $15 \mathrm{~min}$ at $4^{\circ} \mathrm{C}$ and washed with fresh binding buffer. Pellet radioactivity was monitored with a gamma counter. Binding to liver plasma membranes in the presence of $10 \mu \mathrm{mol} / \mathrm{L} \mathrm{SS-14}$ was considered nonspecific binding. The elution profile of the binding assay supernatant was obtained on a Sephadex G-50 Superfine $(100 \mathrm{~cm} \times 1 \mathrm{~cm})$ chromatography column (LKB-Pharmacia, Piscataway, NJ) in $1 \mathrm{M}$ glacial acetic acid as described (14). Stability of ${ }^{125} \mathrm{I}$-[tyr ${ }^{11}$ ]SS-14 incubated for $50 \mathrm{~min}$ with membranes was $92 \%$-identical to stability of ${ }^{125}{ }^{1}-\left[\mathrm{tyr}^{11}\right] \mathrm{SS}-14$ incubated in the absence of rat liver plasma membranes.

Affinity Cross-Linking Protocol. Fifty micrograms of rat liver plasma membranes were incubated in $0.5 \mathrm{ml}$ of binding buffer in the presence or absence of SS-14 with ${ }^{125} \mathrm{I}$ [tyr $\left.{ }^{11}\right]$ SS-14 (150 pmol/L) for $50 \mathrm{~min}$ at $24^{\circ} \mathrm{C}$ (15). In some experiments, we used $10 \mu \mathrm{g}$ membranes and ${ }^{125} \mathrm{I}$-[tyr ${ }^{11}$ ]SS-14 $(30 \mathrm{pmol} / \mathrm{L})$. The mixture was centrifuged at $10,000 \mathrm{~g}$ for 15 min at $4^{\circ} \mathrm{C}$. The pellet was washed in $1.0 \mathrm{ml}$ of ice-cold binding buffer and recentrifuged for $10 \mathrm{~min}$ at $10,000 \mathrm{~g}$ and $4^{\circ} \mathrm{C}$. Three heterobifunctional cross-linking reagents $-N$ hydroxysuccinimidyl 4-azidobenzoate (HSAB), $N$-succinimidyl 6-(azido-2'-nitrophenylamine) hexanoate (SAN-PAH) and $N$-(5-azido-2'-nitrobenzoyloxy)-succinimide (ANB-NOS) were used. The heterobifunctional photoreactive cross-linking reagents were freshly dissolved in DMSO and added at a $1: 100$ dilution to a final concentration of $100 \mu \mathrm{mol} / \mathrm{L}$ to the resuspended pellet. Membrane suspensions were then transferred to 16-mm Costar plates (Costar, Cambridge, MA) and exposed to UV light (275-W sunlamp) at a distance of $15 \mathrm{~cm}$ for $15 \mathrm{~min}$ at $4^{\circ} \mathrm{C}$. Ice-cold buffer containing $2 \mathrm{mmol} / \mathrm{L}$ EDTA was added, and membranes were pelleted. The homobifunctional cross-linking reagent DSS was dissolved in DMSO and added at a $1: 100$ dilution to a final concentration of $1 \mathrm{mmol} / \mathrm{L}$. The reaction was allowed to proceed for $20 \mathrm{~min}$ at $4^{\circ} \mathrm{C}$ and then quenched with $1 \mathrm{ml}$ of $1 \mathrm{~mol} / \mathrm{L}$ ammonium acetate for $5 \mathrm{~min}$ at $24^{\circ} \mathrm{C}$ (16). Pellets were washed with fresh buffer and then subjected to SDS-PAGE.

SDS-PAGE. Affinity cross-linked membranes were solubilized in sample buffer $(0.0625 \mathrm{~mol} / \mathrm{L}$ Tris- $\mathrm{HCl}$ [pH 6.8], $2.3 \%$ SDS [wt/vol], $10 \%$ glycerol [wt/vol], $5 \% \beta$-mercaptoethanol [vol/vol] and $5 \%$ bromphenol blue) by heating at $100^{\circ} \mathrm{C}$ for $3 \mathrm{~min}$. In some studies, $50 \mathrm{mmol} / \mathrm{L}$ dithiothreitol (DTT) was also added (17). Samples were subjected to electrophoresis in $7.5 \%$ or $12 \%$ acrylamide and $1 \%$ SDS. The gels were fixed and dried; autoradiography was performed on dried gels by exposing them to Kodak X-Omat AR film (Eastman Kodak Co., Rochester, NY) with an enhancing screen at $-70^{\circ} \mathrm{C}$. A cross-linking efficiency of $1 \%$ to $2 \%$ was demonstrated by cutting the lanes on some dried gels into $0.5-\mathrm{cm}$ blocks, then measuring each block for radioactivity in a gamma counter.

Plasma Membrane Solubilization. Affinity-labeled membranes $(1 \mathrm{mg} / \mathrm{ml})$ were solubilized in $50 \mathrm{mmol} / \mathrm{L}$ Tris- $\mathrm{HCl}$ and $0.5 \mathrm{mmol} / \mathrm{L}$ benzamidine buffer containing $1 \%$ concentrations of Zwittergent 3-12 (Calbiochem, La Jolla, CA), 3-([3-cholamidopropyl] dimethylammonio)-1-propanesulfonic acid (CHAPS), digitonin or Triton X-100. After gentle agitation for $30 \mathrm{~min}$, the solubilized, affinity-labeled membranes were subjected to centrifugation at $100,000 \mathrm{~g}$ for $60 \mathrm{~min}$ at $4^{\circ} \mathrm{C}(15)$. Supernatant radioactivity was counted in a gamma counter and expressed as counts per minute per milligram of protein.

WGA Adsorption Chromatography. Ten milligrams of WGA-agarose beads in $1.0 \mathrm{ml}$ of $1.0 \mathrm{~mol} / \mathrm{L} \mathrm{NaCl}$ was packed into a $10 \times 0.7 \mathrm{~cm}$ column and washed with $40 \mathrm{ml}$ Tris- $\mathrm{HCl}(50$ $\mathrm{mmol} / \mathrm{L}$ ) containing $1 \%$ Zwittergent 3-12. Solubilized, affinitylabeled complexes were prepared as described above, and the supernatant was applied to the WGA-agarose column (Sigma Chemical Co.). The columns were washed with $\mathrm{Ca}^{++}$buffer until they were free of detectable radioactivity. The column was then washed with $4 \mathrm{mmol} / \mathrm{L} \mathrm{N}, \mathrm{N}^{\prime}, \mathrm{N}^{\prime \prime}$-triacetylchitotriose in buffer containing $1 \%$ Zwittergent 3-12. Two-milliliter fractions were collected, and radioactivity was assayed in a gamma counter (15).

Hydrolysis of Glycoproteins. Hydrolysis of DSS (Pierce Chemical Co., Rockford, IL) cross-linked ${ }^{125} \mathrm{I}$-[tyr $\left.{ }^{11}\right] \mathrm{SS}-14$ binding protein complexes in a volume of $0.1 \mathrm{ml}$ containing 1 unit of endo F, 1\% Zwittergent 3-12 and $20 \mathrm{mmol} / \mathrm{L}$ EDTA in $0.25 \mathrm{~mol} / \mathrm{L}$ sodium acetate was performed at $37^{\circ} \mathrm{C}$ for $1 \mathrm{hr}(18$, 19). The resulting reaction product was pelleted by centrifugation at 2,500 rpm and subjected to SDS-PAGE; this was followed by silver staining and gel autoradiography.

Statistical Analysis. For binding analysis, a multiplevariable curve-fitting program was developed after the method of Munson and Rodbard (20). Scatchard analysis was performed by plotting bound/free ligand vs. bound ligand.

Ethical Considerations. The study protocol was approved by the University of Michigan Committee on Use and Care of Animals.

\section{RESULTS}

Characterization of SS-14 Binding to Liver Plasma Membranes. Specific binding of ${ }^{125} \mathrm{I}-\left[\operatorname{tyr}^{11}\right] \mathrm{SS}-14$ to the rat liver plasma membrane preparation was time dependent. Steady-state binding to the liver plasma membranes reached a plateau by $50 \mathrm{~min}$ (Fig. 1A). At maximal specific binding, nonspecific binding was $30 \%$ to $40 \%$ of total binding. The addition of synthetic SS-14 induced rapid dissociation of the bound radioactivity 

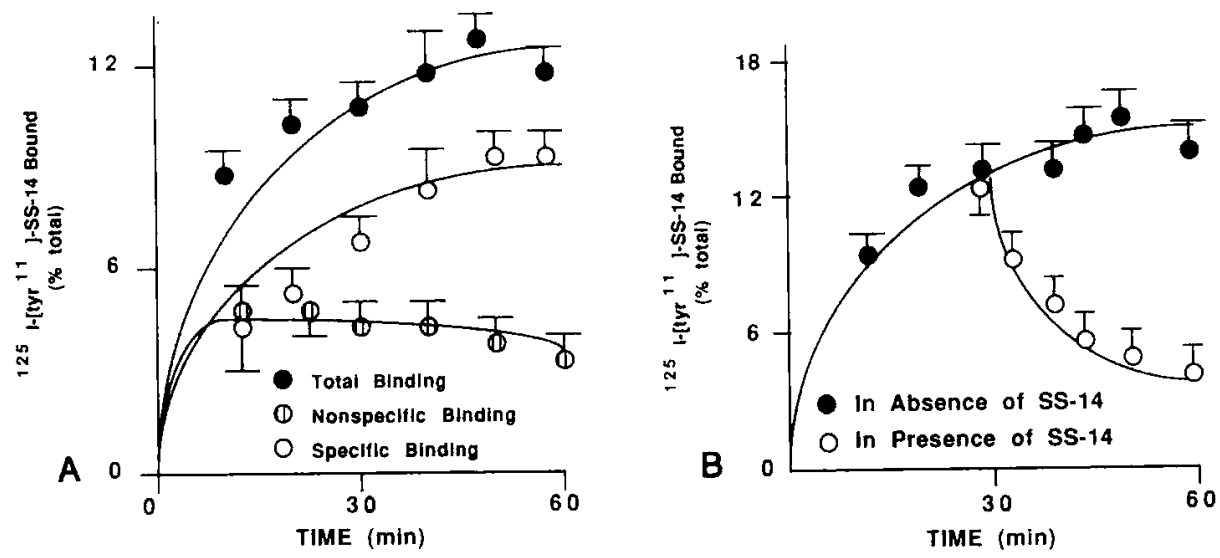

FIG. 1. (A) Time course of binding of $\left.{ }^{125} \mathrm{I}-\mid \mathrm{tyr}^{11}\right] \mathrm{SS}-14$ to rat liver plasma membranes. Rat liver plasma membranes $(20 \mu \mathrm{g} / \mathrm{ml})$ and ${ }^{125} \mathrm{I}$-[tyr ${ }^{11}$ ]SS-14 $(50 \mathrm{pmol} / \mathrm{L})$ were incubated for increasing time intervals in the presence or absence of $10 \mu \mathrm{mol} / \mathrm{L}$ SS-14 (nonspecific) at $24^{\circ} \mathrm{C}$. Each point represents the mean of duplicate determinations of four experiments. Specific binding was obtained by subtracting nonspecific binding from total binding at each point. (B) Dissociation of ${ }^{125} \mathrm{I}$ - [ tyr $\left.{ }^{11}\right] \mathrm{ISS}-14$ from rat liver plasma membranes by unlabeled SS-14. Rat liver plasma membranes $(20 \mu \mathrm{g} / \mathrm{ml})$ and ${ }^{125} \mathrm{I}$-[tyr $\left.{ }^{11}\right] \mathrm{SS}-14(50 \mathrm{pmol} / \mathrm{L})$ were incubated for $30 \mathrm{~min}$, and $10 \mu \mathrm{mol} / \mathrm{L}$ SS-14 was added. The incubation was continued for an additional $30 \mathrm{~min}$. Each point represents the mean of duplicate determinations of three experiments. Specific binding was obtained by subtracting nonspecific binding from total binding at each point. Ninety-two percent of the radioactivity in two supernatants examined eluted as a single peak in the same position as ${ }^{125}$ I-[tyr $\left.{ }^{11}\right] \mathrm{SS}-14$ as determined by chromatography on a Sephadex G-50 column (100 $\times$ $1 \mathrm{~cm}$ ); this was identical to the stability of ${ }^{125} \mathrm{I}-\left[\mathrm{tyr}^{11}\right] \mathrm{SS}-14$ in the absence of membranes. Error bars = S.E.M.

TABLE 1. Relative potency of SS-14 analogs and unrelated peptides in the inhibition of ${ }^{125} I-\left[\right.$ tyr $\left.^{11}\right] \mathrm{SS}-14$ binding to rat liver plasma membranes

\begin{tabular}{lcc}
\hline \multicolumn{1}{c}{ Peptide } & $\begin{array}{c}\mathrm{IC}_{50} \\
(\mathbf{n m o l} / \mathrm{L})\end{array}$ & $\begin{array}{c}\text { Relative } \\
\text { potency }\end{array}$ \\
\hline SS-14 & $0.55 \pm 0.07^{a}$ & - \\
{$\left[\right.$ Tyr $\left.^{0}\right]$ SS-14 } & $1.88 \pm 0.19$ & 0.29 \\
[Tyr $^{1}$ ]SS-14 & $4.09 \pm 0.48$ & 0.13 \\
[Tyr $^{11}$ ]SS-14 & $1.00 \pm 0.09$ & 0.55 \\
[phe $\left.^{4}\right]$ SS-14 & $0.70 \pm 0.08$ & 0.79 \\
[D-trp $\left.^{8}\right]$ SS-14 & $0.21 \pm 0.06$ & 2.62 \\
SS-28 & $0.90 \pm 0.12$ & 0.61 \\
${ }^{1-12}$ SS-28 & $\leq 0.001$ & - \\
\hline
\end{tabular}

$\mathrm{IC}_{50}=50 \%$ inhibitory capacity.

The relative potency of analogs or unrelated peptides (compared with SS-14 taken as unity) was calculated from the concentration of each peptide required to produce half-maximal inhibition of ${ }^{125} \mathrm{I}$ [tyr ${ }^{11}$ ]SS-14 binding to membranes.

${ }^{a}$ Binding data are expressed as mean \pm S.E.M. $(\mathrm{n} \geq 3$ ).

(Fig. 1B). The presence of $0.5 \mathrm{mmol} / \mathrm{L} \mathrm{CaCl}_{2}$ was found to be necessary because no specific binding was observed in the absence of calcium (data not shown). Increasing concentrations of synthetic SS-14 inhibited the binding of ${ }^{125} \mathrm{I}$-[tyr ${ }^{11}$ ]SS-14 to the liver plasma membranes and resulted in a characteristic competition binding profile (Fig. 2). This binding data was transformed into a Scatchard plot indicating the presence of a single class of high-affinity binding sites with an affinity constant $\left(K_{d}\right)$ of $2.4 \pm 0.2 \mathrm{nmol} / \mathrm{L}$ and a binding capacity $\left(\mathrm{B}_{\max }\right)$ of $148 \pm 0.02 \mathrm{fmol} / \mathrm{mg}$ protein (Fig. 2, inset).

The specific binding of ${ }^{125} \mathrm{I}$-[tyr ${ }^{11}$ ]SS-14 to rat liver plasma membranes was further investigated with several synthetic analogs of SS-14. The biologically

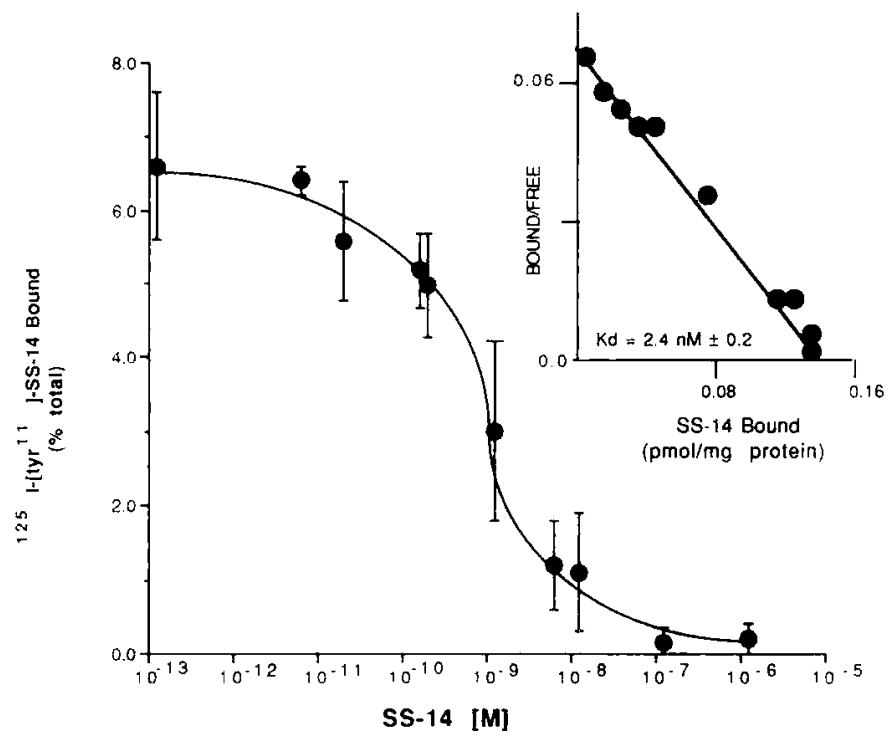

FIG. 2. Displacement of ${ }^{125}$ I-[tyr $\left.{ }^{11}\right]$ SS-14 by increasing concentrations of SS-14. Rat liver plasma membranes $(20 \mu \mathrm{g} / \mathrm{ml})$ and ${ }^{125} \mathrm{I}$ $\left[\right.$ tyr $\left.^{11}\right]$ SS-14 $(50 \mathrm{pmol} / \mathrm{L})$ were incubated with increasing concentrations of unlabeled SS-14 at $24^{\circ} \mathrm{C}$. Points represent averages of five experiments. The Scatchard plot of the binding data is shown in the inset. The maximum binding capacity $\left(\mathrm{B}_{\max }\right)$ was calculated as the intercept on the abscissa; the affinity constant $\left(K_{d}\right)$ was determined from the slope of the line $(r=0.96)$. Error bars $=$ S.E.M.

active analog $\left[\mathrm{D}-\operatorname{trp}^{8}\right] \mathrm{SS}-14$ was the most potent in inhibiting ${ }^{125} \mathrm{I}$-[tyr $\left.{ }^{11}\right] \mathrm{SS}-14$ binding to the rat liver plasma membrane; other analogs-[tyr $\left.{ }^{0}\right] \mathrm{SS}-14$, [tyr ${ }^{1}$ SS-14, [tyr $\left.{ }^{11}\right] \mathrm{SS}-14$ and SS-28-were comparatively less potent than [D-trp $\left.{ }^{8}\right]$ SS-14. ${ }^{1-12}$ SS-28, a somatostatin analog lacking the biologically active portion of the molecule, and the unrelated peptides substance $P$, 


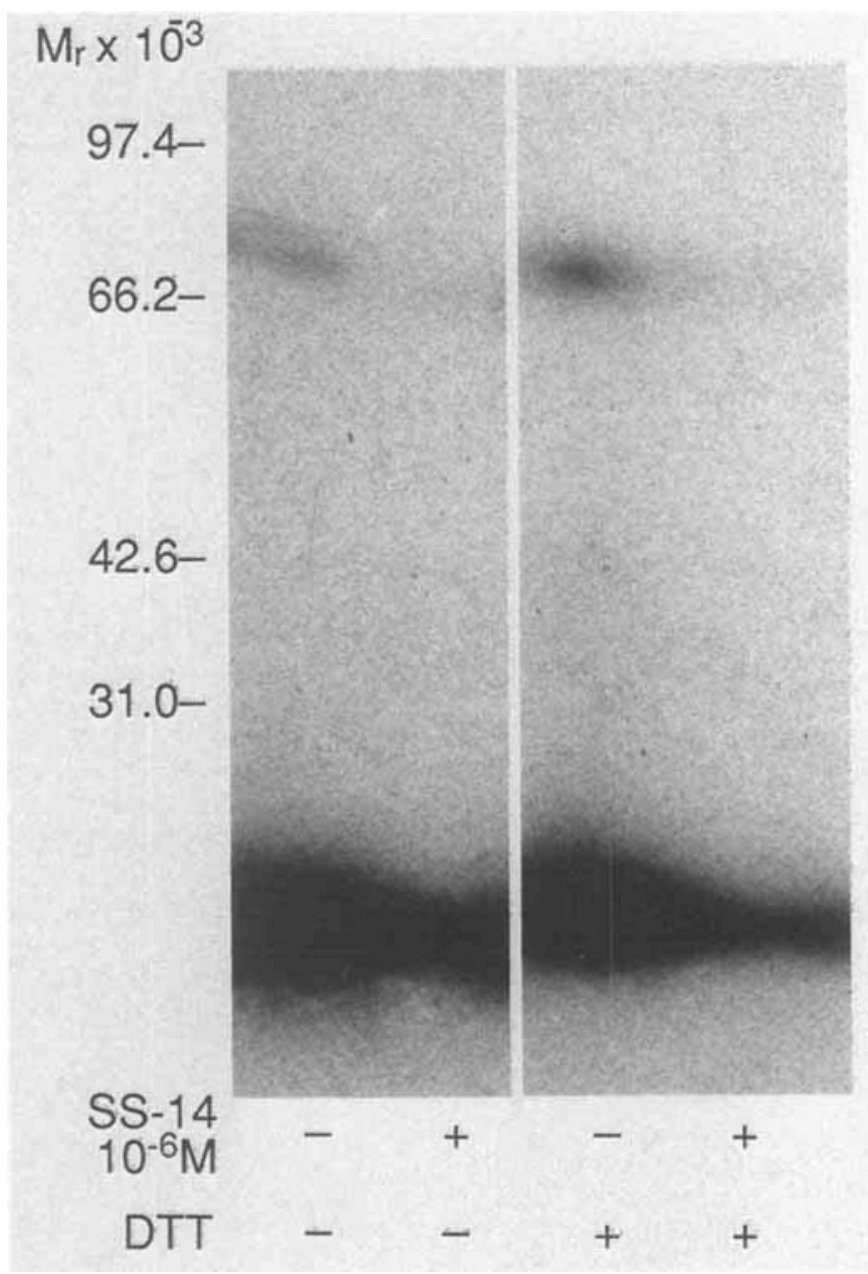

FiG. 3. SDS-PAGE of ${ }^{125}{ }^{-}-\left[\right.$tyr $\left.^{11}\right]$ SS-14 cross-linked to its binding protein in rat liver plasma membranes. Liver plasma membranes (50 $\mu \mathrm{g})$ were incubated for $50 \mathrm{~min}$ at $24^{\circ} \mathrm{C}$ with ${ }^{125} \mathrm{I}$ - $\left[\right.$ tyr $\left.^{11}\right] \mathrm{SS}-14$ (150 $\mathrm{pmol} / \mathrm{L})$. The SS-14/protein complex was cross-linked with $100 \mu \mathrm{mol} / \mathrm{L}$ DSS for $15 \mathrm{~min}$. Cross-linked complexes were then subjected to SDS-PAGE (12\%). Data are representative of three experiments.

gastrin, motilin and gastrin-releasing peptide were unable to displace ${ }^{125} \mathrm{I}$-[tyr ${ }^{11}$ ]SS-14 (Table 1).

Covalent Cross-linking of ${ }^{125} I-[t y r]^{11}$ SS-14 to Its Binding Protein. To study the biochemical nature and molecular weight of the binding protein, ${ }^{125} \mathrm{I}-$ [tyr $\left.{ }^{11}\right] \mathrm{SS}-14$ was incubated with the plasma membranes; the bound complex was then covalently crosslinked. One homobifunctional cross-linking reagent, DSS, and three heterobifunctional cross-linking reagents-HSAB, SAN-PAH and ANB-NOS-were used. DSS was found to be the most efficient. Among the three heterobifunctional cross-linking reagents, ANB-NOS was the most efficient (Table 2). The crosslinking efficiency was $1 \%$ to $2 \%$, in agreement with the work of Susini et al. (15). Autoradiograms from SDS-PAGE gels of the cross-linked ${ }^{125} \mathrm{I}-$ [tyr $\left.^{11}\right] \mathrm{SS}-14$ complexes showed a broad band of radioactivity of mol wt 70,000 $\mathrm{Da}$ after subtraction of $1,780 \mathrm{Da}$ for the calculated molecular weight of ${ }^{125} \mathrm{I}_{-}\left[\mathrm{tyr}^{11}{ }^{11} \mathrm{SS}-14\right.$. The
TABLE 2. Affinity cross-linking of ${ }^{125}$ I-[tyr $\left.{ }^{11}\right] \mathrm{SS}-14$ to rat liver plasma membranes by various reagents

\begin{tabular}{cc}
\hline Reagent & cpm $\left(\times \mathbf{1 0}^{-2}\right)$ \\
\hline DSS $(1 \mathrm{mmol} / \mathrm{L})$ & $46.50 \pm 3.55^{a}$ \\
HSAB $(0.1 \mathrm{mmol} / \mathrm{L})$ & $8.74 \pm 0.61$ \\
SAN-PAH $(0.1 \mathrm{mmol} / \mathrm{L})$ & $8.63 \pm 0.41$ \\
ANB-NOS $(0.1 \mathrm{mmol} / \mathrm{L})$ & $10.58 \pm 0.58$ \\
\hline
\end{tabular}

Membranes $(50 \mu \mathrm{g})$ were incubated with ${ }^{125} \mathrm{I}$-[tyr $\left.{ }^{11}\right] \mathrm{SS}-14(150$ pmol/L) for 50 min at $24^{\circ} \mathrm{C}$ and cross-linked with one of four reagents in the concentration noted. Binding and cross-linking with reagents were performed as described in "Materials and Methods" (at least four experiments per reagent).

${ }^{a}$ Data expressed as mean \pm S.E.M.

TABLE 3. Solubility of cross-linked ${ }^{125} \mathrm{I}-\left[\mathrm{tyr}^{11}{ }^{1 \mathrm{SS}-14}\right.$ to rat liver plasma membrane complexes in nonreducing detergents

\begin{tabular}{lc}
\hline \multicolumn{1}{c}{ Detergent } & ( $\mathrm{CPM}$ \\
\hline Zwittergent $3-12$ & $1.10 \pm 0.26^{a}$ \\
CHAPS & $0.97 \pm 0.17$ \\
Digitonin & $\leq 0.02$ \\
Triton X-100 & $\leq 0.02$ \\
\hline
\end{tabular}

Rat liver plasma membranes $(50 \mu \mathrm{g})$ were incubated with ${ }^{125} \mathrm{I}$ [tyr ${ }^{11}$ ]SS-14 (150 pmol/L), cross-linked with DSS $(100 \mu \mathrm{mol} / \mathrm{L})$ and solubilized at a concentration of $1 \mathrm{mg} / \mathrm{ml}$ with $1 \%$ detergent for $2 \mathrm{hr}$ at $4^{\circ} \mathrm{C}$. After centrifugation, the supernatant was aspirated, and radioactivity was quantitated (at least four experiments per reagent).

Data expressed as mean \pm S.E.M.

presence of this band was eliminated by the addition of $10 \mu \mathrm{mol} / \mathrm{L} \mathrm{SS}-14$ during cross-linking (Fig. 3). Addition of $50 \mathrm{mmol} / \mathrm{L}$ DTT did not alter the position or number of protein bands at mol wt 70,000 Da (Fig. 3).

Solubilization of Cross-linked Binding Protein Complexes in Nondenaturing Detergents. To further characterize the SS-14 binding protein, it was necessary to solubilize the labeled complex in nondenaturing detergents. To investigate the solubility of the binding protein, $1 \%$ solutions of four detergents (Zwittergent 3-12, CHAPS, digitonin and Triton X-100) were used. Specific binding sites were saturated with ${ }^{125} \mathrm{I}$ [tyr ${ }^{11}$ ]SS-14 (150 pmol/L) and then cross-linked with DSS. Increased labeling was not associated with increased nonspecific binding. Of the four detergents used, Zwittergent 3-12 and CHAPS were associated with essentially complete solubilization of the labeled complexes (Table 3).

Binding of Cross-linked Complexes to WGA-Agarose Chromatography Columns. To ascertain whether the cross-linked labeled protein was glycosylated, we used WGA column chromatography and SDS-PAGE autoradiography. DSS cross-linked labeled protein was solubilized in a $1 \%$ solution of Zwittergent 3-12. Solubilized complexes were adsorbed on a WGA-agarose column. Most of the noncovalently cross-linked radioactivity eluted in the first two fractions. After we achieved a 


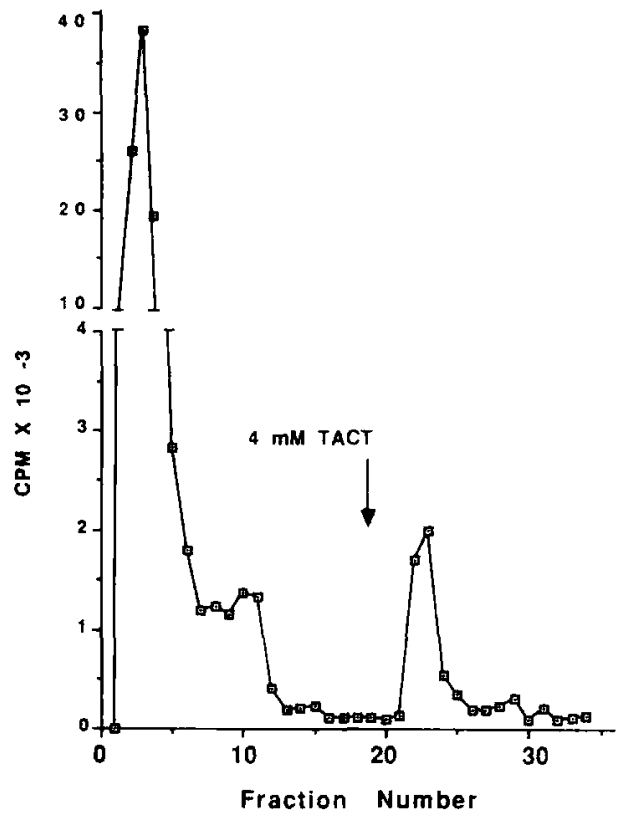

Fig. 4. Chromatography of affinity-labeled SS-14 binding proteins on WGA-agarose. Fifty micrograms of liver plasma membranes were incubated with ${ }^{125} \mathrm{I}$-[tyr $\left.{ }^{11}\right] \mathrm{SS}-14(150 \mathrm{pmol} / \mathrm{L})$, cross-linked with 100 $\mu \mathrm{mol} / \mathrm{L}$ DSS for $15 \mathrm{~min}$ and solubilized with $1 \%$ Zwittergent 3-12 (for details, see Fig. 3 legend and "Materials and Methods"). Fifty micrograms of protein was applied to a WGA affinity column. The column was washed until no residual activity was noted in the eluate. Bound protein was then eluted with $4 \mathrm{mmol} / \mathrm{L} \mathrm{N}, \mathrm{N}^{\prime}, \mathrm{N}^{\prime \prime}$ triacetylchitotriose $(T A C T)$ as described. Fractions $(2.0 \mathrm{ml})$ were collected, and radioactivity was measured. Data are representative of four experiments.

plateau, buffer containing $4 \mathrm{mmol} / \mathrm{L} N, \mathrm{~N}^{\prime}, \mathrm{N}^{\prime \prime}$ triacetylchitotriose was added and an additional radioactive peak was eluted (Fig. 4)

Treatment of DSS cross-linked ${ }^{125} \mathrm{I}-\left[\mathrm{tyr}^{11}\right] \mathrm{SS}-14$ binding protein complexes with endo $F$ before WGA column chromatography resulted in loss of binding (Fig. 5). The decrease in the amount of noncovalent crosslinked radioactivity that eluted in the initial two fractions in the control sample in comparison to Figure 4 reflects an extra wash with buffer. Although deglycosylation by endo F of DSS cross-linked ${ }^{125} \mathrm{I}$-[ tyr $^{11}$ ]SS-14 binding proteins abolished binding to WGA-agarose columns, no significant alteration in migration on SDS-PAGE autoradiography could be noted (Fig. 6).

Effect of Nucleotides on the Binding of ${ }^{128}$ I-[tyr $\left.{ }^{1}\right]$ SS. 14. A well-known characteristic of binding proteins documented to be receptors is the demonstration of coupling to $G$ proteins and regulation by guanine nucleotides (16). We investigated the effects of several nucleotides on ${ }^{125} \mathrm{I}$-[tyr ${ }^{11}$ ]SS-14 binding to liver plasma membranes (Fig. 7 A,B). The specific binding of ${ }^{125} \mathrm{I}$ [tyr ${ }^{11}$ ]SS-14 was inhibited by GTP and GDP with approximately equal potency, whereas GMP did not inhibit specific binding (Fig. 7A). The addition of pyruvate kinase and phosphoenol pyruvate to regenerate GTP from GDP increased the inhibition of binding, indicating that the membrane preparation can

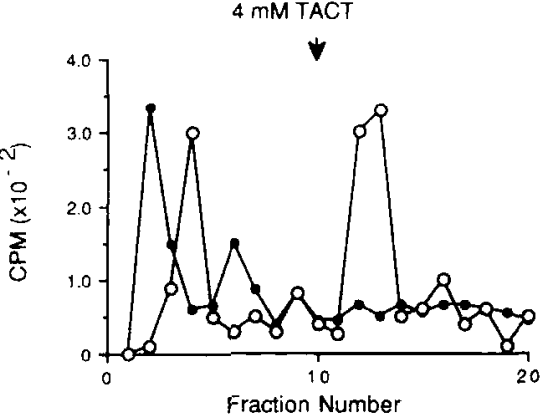

FIG. 5. Chromatography of endo-F-treated SS-14 binding proteins to WGA agarose. Membranes (10 $\mu \mathrm{g}$ ) were labeled with ${ }^{125} \mathrm{I}$ [tyr ${ }^{11}$ ]SS-14 (30 pmol/L), cross-linked with $100 \mu \mathrm{g}$ DSS for $15 \mathrm{~min}$ and solubilized in Zwittergent 3-12. Membranes were treated with endo F (•) or buffer $(0)$ as described (see "Materials and Methods"). The column was washed until it was free of residual radioactivity; then $4 \mathrm{mmol} \mathrm{N}, \mathrm{N}^{\prime}, \mathrm{N}^{\prime \prime}$-triacetylchitotriose (TACT) was added as indicated. Data are representative of three experiments.

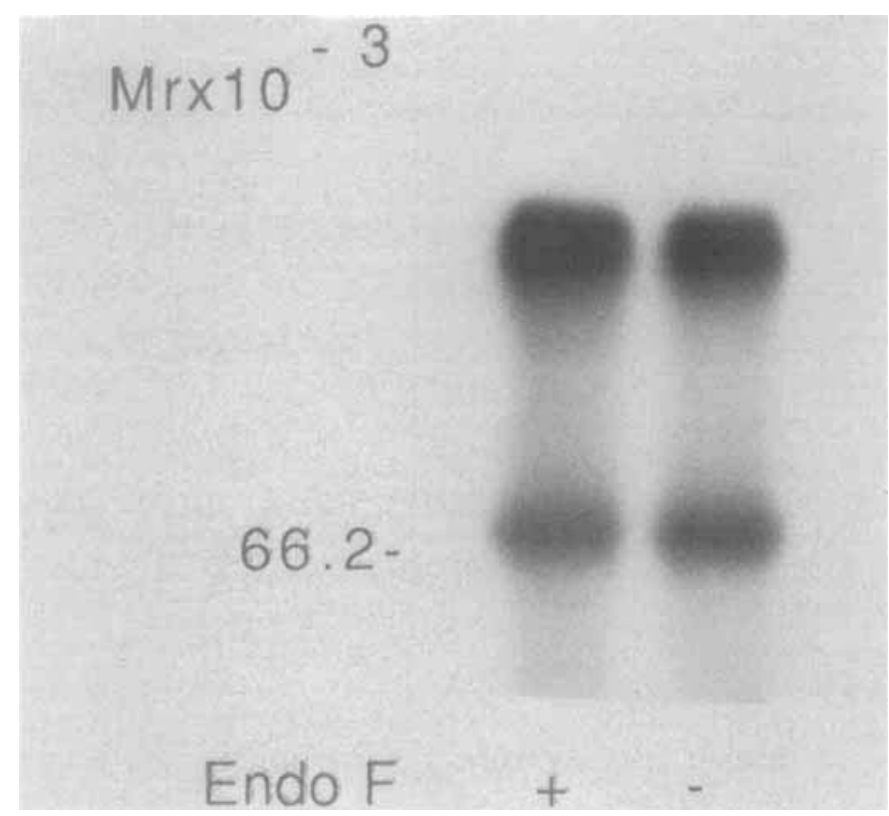

FTG. 6. SDS-PAGE of ${ }^{125} \mathrm{I}$-[tyr ${ }^{11}$ ]SS-14 cross-linked to solubilized, endo-F-treated membranes. Liver plasma membranes $(50 \mu \mathrm{g})$ were incubated for $50 \mathrm{~min}$ at $24^{\circ} \mathrm{C}$ with ${ }^{125} \mathrm{I}$-[tyr $\left.{ }^{11}\right] \mathrm{SS}-14(150 \mathrm{pmol} / \mathrm{L})$. The SS-14/protein complex was cross-linked with $100 \mu \mathrm{mol} / \mathrm{L}$ DSS. Cross-linked complexes were then subjected to hydrolysis by endo $F$; this was followed by SDS-PAGE (12\%). Data are representative of four experiments.

hydrolyse GTP. In each experiment, care was taken to adjust the $\mathrm{pH}$ in an attempt to prevent acidic dissociation of ${ }^{125} \mathrm{I}$-[tyr ${ }^{11}$ ]SS-14 to the membrane protein.

We further compared the effects of GTP with the nonhydrolyzable GTP analog guanosine-5'-0-(3-thiotriphosphate) (GTPyS) and ATP on the binding of ${ }^{125}$ I-[tyr $\left.{ }^{11}\right] S S-14$ to the liver plasma membranes. Liver plasma membranes were incubated at $24^{\circ} \mathrm{C}$ with ${ }^{125} \mathrm{I}-\left[\mathrm{tyr}^{11}\right] \mathrm{SS}-14$ in the presence of various concentra- 

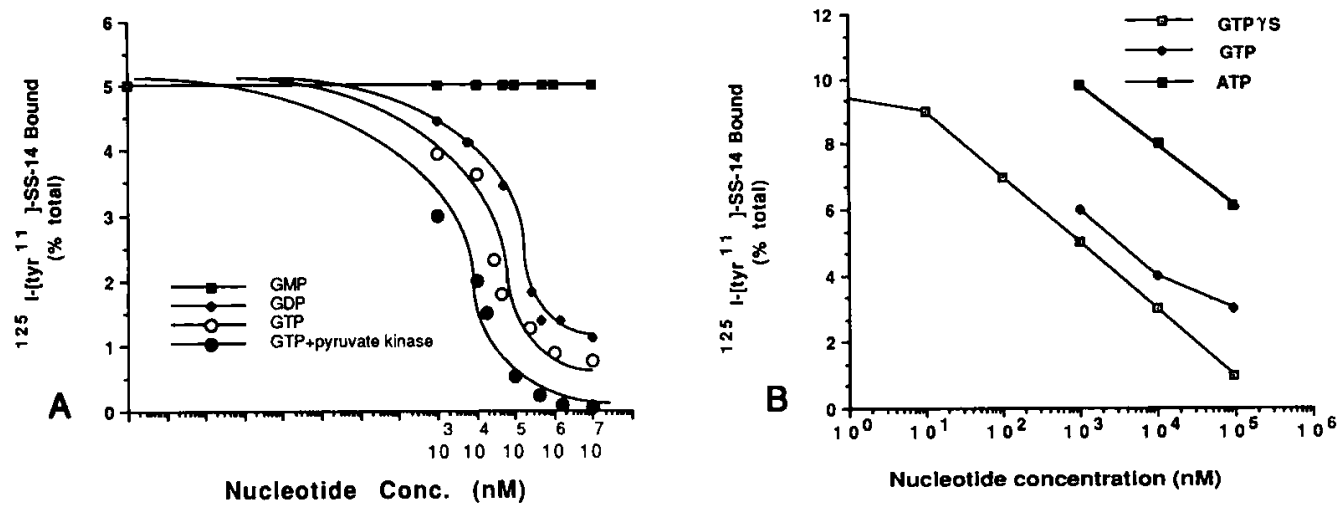

Fig. 7. (A) Effect of guanine nucleotides on SS-14 binding to rat liver plasma membranes. Rat liver plasma membranes (20 $\mu \mathrm{g}$ ) were incubated with ${ }^{125} \mathrm{I}$-[tyr ${ }^{11}$ ]SS-14 (50 pmol/L) for $50 \mathrm{~min}$ in the presence of various concentrations of GMP, GDP and GTP and a GTP-regenerating system $(20 \mathrm{U} / \mathrm{ml}$ pyruvate kinase and $10 \mathrm{mmol} / \mathrm{L}$ phosphoenolpyruvate). Each point represents the mean of duplicate determinations, and the data are representative of three experiments. (B) Effect of GTP $\gamma$ S and ATP on SS-14 binding to rat liver plasma membranes. Rat liver plasma membranes $(20 \mu \mathrm{g})$ were incubated with ${ }^{125} \mathrm{I}$-[tyr $\left.{ }^{11}\right] \mathrm{SS}-14(50 \mathrm{pmol} / \mathrm{L})$ for $50 \mathrm{~min}$ in the presence or absence of increasing concentrations of nucleotides (GTP $\gamma$ S, GTP or ATP). Each point represents the mean of duplicate determinations, and the data are representative of three experiments.

tions of GTP, GTP yS and ATP; again, care was taken to adjust the $\mathrm{pH}$. GTP and GTP $\gamma \mathrm{S}$ inhibited the binding of ${ }^{125}$ I-[tyr ${ }^{11}$ ]SS-14 in a dose-dependent manner (Fig. 7B). The binding of ${ }^{125} \mathrm{I}$-[tyr ${ }^{11}$ ]SS-14 appeared to be specifically decreased by guanine nucleotides because $10^{-4}$ $\mathrm{mol} / \mathrm{L}$ ATP had only an attenuated effect.

\section{DISCUSSION}

In this study, we demonstrated the presence of specific binding sites for iodinated SS-14 on rat liver plasma membranes. Specific binding was time dependent, saturable and reversible. The calculated affinity of 2.4 $\mathrm{nmol} / \mathrm{L}$ is similar to that of other sites in the gastrointestinal tract, specifically the stomach and pancreas $(12,16$, 17). Our finding of the need for $\mathrm{Ca}^{++}$in the binding buffer for iodinated SS-14 to specifically bind to liver plasma membranes is in agreement with that reported for SS-14 binding to its receptor on pancreatic plasma membranes $(16,17)$ and for cyclosomatostatin binding to the hepatocytes (9). Sato et al. (10) used Krebs-Ringer bicarbonate buffer containing glucose and BSA without calcium salts; they observed no specific SS-14 binding to the liver cell surface (10). This data further emphasizes the necessity of $\mathrm{Ca}^{++}$in any binding assay buffer.

In isolated rat liver, it has been shown that $27 \%$ of SS-28 is converted to SS-14 (21). Conlon et al. observed less than $10 \%$ degradation of ${ }^{125} \mathrm{I}$-[tyr $\left.{ }^{11}\right] \mathrm{SS}-14$ when it was exposed to hepatocytes in vitro (22). In this study, we used $20 \mu \mathrm{g}$ of the membranes at $24^{\circ} \mathrm{C}$ and have recovered $92 \%$ of the radioactivity as intact tracer as measured by Sephadex G-50 column chromatography. Taken together, the data suggest that isolated membranes are the best available model for the study of liver membrane SS-14 binding proteins (12, 15-17).

Displacement of ${ }^{125} \mathrm{I}$-[tyr ${ }^{11}$ ]SS-14 with biologically active somatostatin analogs, but not by biologically inactive ${ }^{1-12}$ SS-28 or other unrelated peptides, was demonstrated (Table 1). Because SS-14 is thought to be the physiological ligand for the SS-14 receptor, the ability of SS-14 analogs to displace ${ }^{125} \mathrm{I}_{-}\left[\right.$tyr $\left.^{11}\right] \mathrm{SS}-14$ was judged with SS-14 as the standard. Interestingly, [tyr ${ }^{11}$ ]SS-14 and other tyrosinylated analogs were less capable of displacement of radioligand than was SS-14. SS-14 analogs modified in the ring portion of the molecule-especially at position 8 , such as D-trp ${ }^{8}$ - were more potent in displacing SS-14, in accordance with data reported in pancreatic acinar membranes (16). The relative potency of each analog in inhibiting binding of ${ }^{125} \mathrm{I}$-[tyr ${ }^{11}$ ]SS-14 to liver plasma membranes also correlated with known biological potency (Table 2; 16, 17, 21). The data support the contention that binding of ${ }^{125} \mathrm{I}$-[tyr $\left.{ }^{11}\right] \mathrm{SS}-14$ to liver plasma membranes is specific.

To further characterize the nature of the SS-14 binding sites, ${ }^{125}$ I-[tyr $\left.{ }^{11}\right] \mathrm{SS}-14$ was cross-linked to binding sites on the rat liver plasma membranes with one homobifunctional and three heterobifunctional cross-linking reagents, as described previously, to study peptide hormone receptors $(15,16)$. Of the four crosslinking reagents used, the homobifunctional reagent DSS was found to be the most efficient. The data are similar to that found for SS-14 binding in pancreas (16). Our finding of a labeled band at mol wt 70,000 Da suggests that the binding site is a protein of 70,000 Da and similar to that reported by Ogawa (8). Complete absence of this band in the presence of $10 \mu \mathrm{mol} / \mathrm{L}$ SS-14 further confirms the saturability of the binding (Fig. 3). Identification of the band in the same position in presence of the reducing agent DTT also suggests that the SS-14 binding protein does not contain sulfhydryl linkages or subunits (15). The meaning of observed variations in the reported size of SS-14 receptors is unknown; however, the finding of an SS-14 binding protein with an approximate mol wt $70,000 \mathrm{Da}$ in this study, one of 92,000 Da in pancreas (17) and another of $60,000 \mathrm{Da}$ in brain (23) could be due to alternative messenger RNA processing or posttranslational processing of a common protein $(24,25)$. Such molecular 
variations might explain functional differences in SS-14 receptor subtypes $(26,27)$.

The band of cross-linked radioactivity is somewhat broad (Fig. 3) and suggests that it is a glycoprotein (28). To further investigate the possibility that sugar moieties were present, the cross-linked, radiolabeled binding protein was first solubilized in nondenaturing detergents. Zwittergent 3-12 and CHAPS were most efficient, similar to findings in pancreatic and brain membranes $(15,23)$. Adsorption of the cross-linked SS-14 binding protein by WGA-agarose columns and elution by a competing sugar, $\mathrm{N}, \mathrm{N}^{\prime}, \mathrm{N}^{\prime \prime}$-triacetylchitotriose (Fig. 4), suggest that the cross-linked SS-14 binding protein is indeed a glycoprotein and supports previous observations that a broad band on SDS-PAGE is an indication of the presence of glycosylation (28). No increased migration of the radioactive band is seen on SDS-PAGE, despite the loss of binding to WGA columns after endo $F$ treatment of DSS cross-linked ${ }^{125}$ I-[tyr $\left.{ }^{11}\right]$ SS-14 binding proteins, suggesting that the SS-14 binding protein is only sparsely glycosylated with mannose oligosaccharides to a degree not resolvable by PAGE (18).

In summary, we showed that the specific binding of ${ }^{125}$ I-[tyr ${ }^{11}$ ]SS-14 to liver plasma membranes is inhibited by the presence of GMP, GDP, GTP and GTP with pyruvate kinase (Fig. 7A), suggesting regulation by guanine nucleotide binding proteins ( $G$ proteins). The data support the hypothesis that $G$ proteins may mediate SS-14-inhibited cyclic AMP synthesis in hepatocytes (4). The potential interaction of the ${ }^{125} \mathrm{I}$ [tyr ${ }^{11}$ ]SS-14 binding protein with $\mathrm{G}$ proteins is further supported by the observation of increasing inhibition of binding of ${ }^{125}$ I-[tyr ${ }^{11}$ ]SS-14 to liver plasma membranes in the presence of GTPyS (Fig. 7B). The demonstration of a SS-14-specific, saturable, hepatocyte membrane binding protein; the biochemical characteristics; and the inhibition of binding by guanine nucleotides all suggest that this protein functions as a hepatic SS-14 receptor.

\section{REFERENCES}

1. Itoh M, Mandarino L, Gerich GE. Anti-somatostatin gammaglobulin augments secretion of both insulin and glucagon in vitro: evidence for a physiological role for endogenous somatostatin in the regulation of pancreatic $A$ - and $B$-cell function. Diabetes 1980;29:693-695.

2. Martin JB, Brazeau P, Renaud JP. Hypothalamic peptides: new evidence for peptidergic pathways in the CNS. Lancet 1975;2: 393-395.

3. Catalan RE, Avila C, Vila T, Castillon MP. Somatostatin effect on cyclic-AMP levels mediated by glucagon stimulation in rat liver. Metabolism 1978;27:1359-1360.

4. Raper SE, Kothary PC, Kokudo N. Somatostatin-14 blocks the hepatotrophic effect of insulin in the rat. J Surg Res 1991;50; 386-390.

5. Sacks H, Waligora $\mathrm{K}$, Matthews J, Pimstone BL. Inhibition by somatostatin of glucagon-induced glucose release from the isolated perfused rat liver. Endocrinology 1977;101:1751-1759.

6. Weinstein I, Wasfi I, Heimberg M. Lack of effect of somatostatin on the glucagon-induced alterations of hepatic metabolism of $\left[1-{ }^{14} \mathrm{C}\right]$ oleate. Biochim Biophys Acta 1981;664:124-132.

7. Sacks HS, Terry LC, Wright RK, Stentz FB. Somatostatin metabolism: differences in clearance of $\mathrm{N}$-terminal and central portions of molecule during perfusion of rat liver. Am $\mathbf{J}$ Physiol 1984;246:G226-G234

8. Ogawa $\mathrm{N}$, Thompson $\mathrm{T}$, Friesen HG. Characteristics of a somatostatin-binding protein. Can J Physiol Pharmacol 1977;56: 48-53.

9. Ziegler K, Frimmer M, Kessler H, Haupt A. Azidobenzamido-008, a new photosensitive substrate for the "multispecific bile acid transporter" of hepatocytes: evidence for a common transport system for bile acids and cyclosomatostatins in basolateral membranes. Biochim Biophys Acta 1988;945:263-272.

10. Sato H, Sugiyama Y, Sawada Y, Iga Y, Sakamoto S, Fuwa T, Hanano M. Dynamic determination of kinetic parameters for the interaction between polypeptide hormones and cell-surface receptors in the perfused rat liver by the multiple-indicator dilution method. Proc Natl Acad Sci USA 1988;85:8355-8359.

11. Ray TK. A modified method for the isolation of the plasma membrane from rat liver. Biochim Biophys Acta 1970;196:1-9.

12. Park J, Chiba T, Yokotani K, DelValle J, Yamada T. Somatostatin receptors on canine fundic D-cells: evidence for autocrine regulation of gastric somatostatin. Am J Physiol 1989;257:G235-G241.

13. Pardridge WM, Eisenberg J, Yamada T. Rapid sequestration and degradation of somatostatin analogues by isolated brain $\mathrm{mi}$ crovessels. J Neurochem 1985;44:1178-1184.

14. Bohlen $P$, Benoit $R$, Ling N, Guillemin $R$, Brazeau P. Isolation and characterization of rat hypothamalic somatostatin-14. Endocrinology 1981;108:2008-2010.

15. Susini C, Bailey A, Szecowka J, Williams JA. Characterization of covalently cross-linked pancreatic somatostatin receptors. J Biol Chem 1986;261:16738-16743.

16. Srikant CB, Patel YC. Somatostatin receptors on pancreatic acinar cells: pharmacological and structural characterization and demonstration of down-regulation in streptozotocin diabetes. J Biol Chem 1986;261:7690-7696.

17. Sakamoto C, Goldfine ID, Williams JA. The somatostatin receptor on isolated pancreatic acinar cell plasma membranes: Identification of subunit structure and regulation by cholecystokinin. J Biol Chem 1984;259:9623-9627.

18. Tarentino AL, Gomez CM, Plummer TH. Deglycosylation of asparagine-linked glycans by peptide: $\mathrm{N}$-glycosidase $\mathrm{F}$. Biochemistry $1985 ; 24: 4665-4671$.

19. Alexander S, Elder JH. Endoglycosidases from Flavobacterium meningosepticum application to biological problems. Methods Enzymol 1989;179:505-518.

20. Munson PJ, Rodbard D. LIGAND: A versatile computerized approach for characterization of ligand-binding systems. Anal Biochem 1980;107:220-239.

21. Ruggere MD, Patel YC. Hepatic metabolism of somatostatin-14 and somatostatin-28: immunohistochemical characterization of the metabolic fragments and comparison of cleavage sites. Endocrinology 1985;117:88-96.

22. Conlon JM, Whittaker J, Hammond V, Alberti KGMM. Metabolism of somatostatin and its analogues by the liver. Biochim Biophys Acta 1981;677:234-242.

23. He HT, Johnson $K$, Thermos $K$, Reisine $T$. Purification of a putative brain somatostatin receptor. Proc Natl Acad Sci USA 1989;86:1480-84.

24. Bonner TI, Buckley NJ, Young AC, Brann MR. Identification of a family of muscarinic acetylcholine receptor genes. Science 1987; 237:527-532

25. Thermos K, Reisine $T$. Somatostatin receptor subtypes in the clonal anterior pituitary cell lines AtT-20 and GH3. Mol Pharmacol 1988;33:370-377.

26. Mandarino L, Stenner D, Blanchard W, Nissen S, Gerich J, Ling N, Brazeau P, et al. Selective effects of somatostatin-14, -25 and -28 on in vitro insulin and glucagon secretion. Nature (London) 1981;291:76-78.

27. Brown M, Rivier J, Vale W. Somatostatin-28: selective action on the pancreatic B-cell and brain. Endocrinology 1981;108:23912393.

28. Hames BD. An introduction to polyacrylamide gel electrophoresis. In: Hames BD, Rockwood D, eds. Gel electrophoresis of protein: a practical approach. Oxford: IRL Press, 1981:1-59. 